\title{
Mantle Melting Beneath MID-OCEAN RIDGES
}

BY CHARLES H. LANGMUIR AND DONALD W. FORSYTH

The plate-tectonic revolution was initially "kinematic" a description of plate motions across Earth's surface. Plate tectonics is now recognized as the surface manifestation of a greater process - circulation of the solid earth. Magma ascends to the surface at mid-ocean-ridge spreading centers to cool and form oceanic crust, which millions of years later returns to the mantle at subduction zones. Formation of oceanic crust is the greatest contribution of flow from our planet's interior, as twothirds of the earth is resurfaced about every 100 million years.

Partial melting of the mantle at spreading centers is the mechanism by which this flow takes place, and thus is fundamental to understanding solid-earth circulation.

Melting is a primary means by which the earth cools: seafloor spreading brings hot mantle from depth to the colder surface. Because we normally think that melting occurs through heating (e.g., putting a slab of butter in a frying pan), it may seem paradoxical to say the earth melts while cooling down. The explanation for this paradox is that melting temperatures are dependent on pressure as well as temperature. Just as increased temperature excites atoms so they free themselves from their ordered, solid, crystalline state, so increased pressure squeezes atoms, making it more difficult for them to transition from solid to liquid. Thus, temperature and pressure exert opposite effects on melting, and melting can occur by decreasing pressure at a given temperature as well as by increasing temperature at a given pressure. The reason melting by pressure release seems foreign to common experience is because human life on Earth is lived in an environment of almost constant pressure caused by the weight only of the atmosphere. The solid earth, however, is subject to huge changes in pressure, because the weight of hundreds of kilometers of rock exerts pressures equivalent to thousands of atmospheres in the interior. As mantle ascends beneath the mid-ocean ridge, less and less rock lies above it, so large pressure changes occur, which leads to melting. The melt is less dense than the solid, and rises to the surface to form the oceanic crust.

Figure 1 shows how rising mantle crosses the "solidus" (the transition from complete solid to partial melt) and melts progressively towards the surface. Note that because the mantle is a solid consisting of many different molecules, it does not melt entirely at a single temperature, but progressively over a range of temperatures - from 0 percent melting at the solidus to 100 percent melting several hundred degrees higher at the liquidus. Thus, partial melting is possible.

Several lines of evidence provide information about this melting process. New maps generated over the past 25 years show the variations in shape and depth of thousands of volcanoes distributed along the ridge. These maps have enabled scientists to sample the volcanic rocks-ocean-ridge basalt- that make up the surface pavement of the oceanic crust. About 80 percent of the 60,000 -kilometer-long mid-ocean ridge has been mapped and sampled at least to $100-\mathrm{km}$ spacing (see www.petdb.org). At the same time, experimental studies have led to quantitative models of how melt composition and amount vary with temperature and pressure (e.g., Jacques and Green, 1980; Kinzler and Grove, 1992; Baker and Stolper, 1994; Pickering-Witter and Johnston, 2000). And seismic studies, which are able to probe Earth's interior directly, provide information about the "melting regime" beneath the ridge axis. This article synthesizes some of these developments, and outlines a set of major questions for future research. 


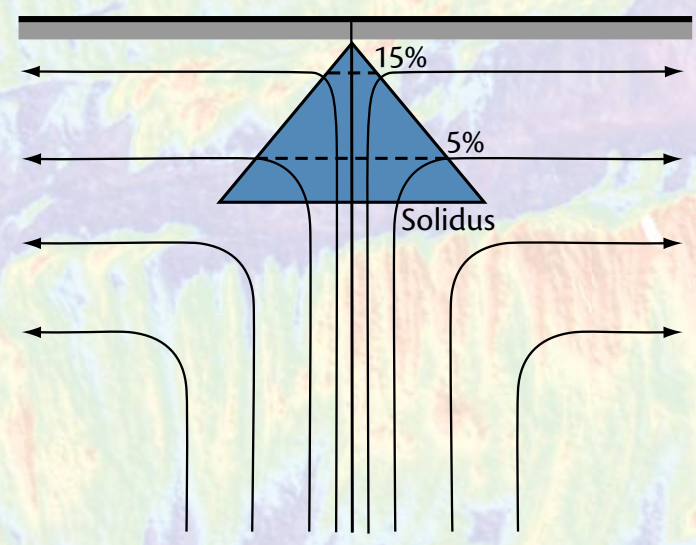

Cold Ascending Mantle

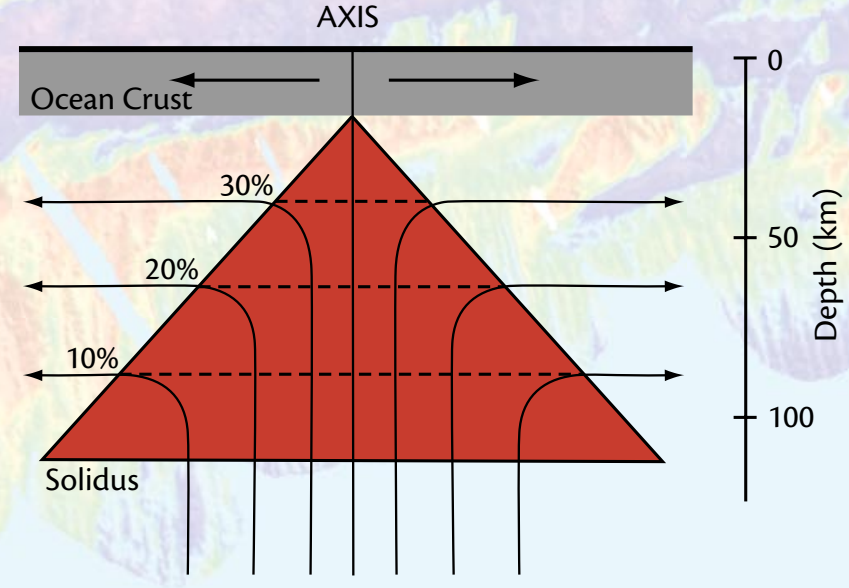

Hot Ascending Mantle
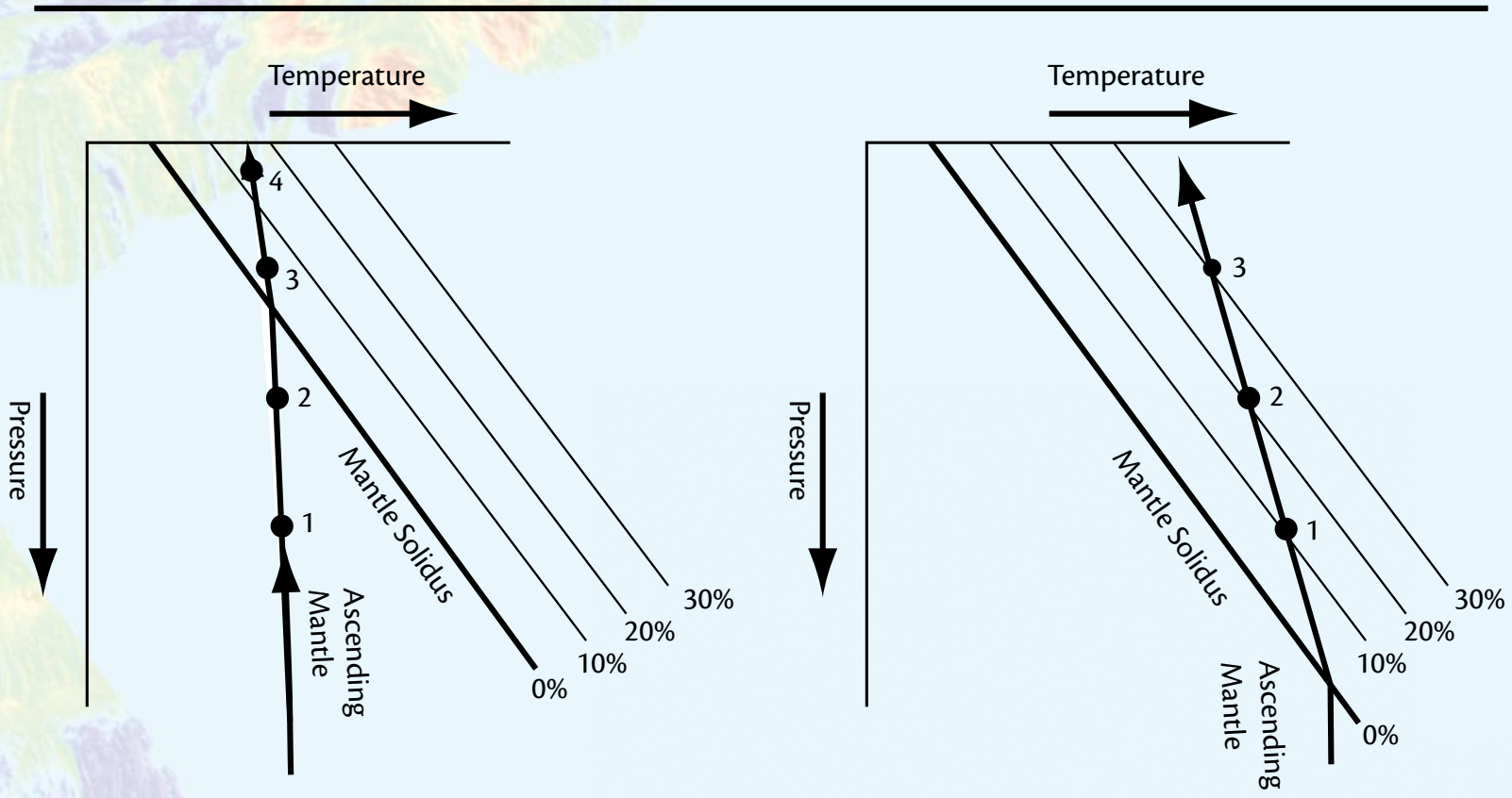

Figure 1. Diagrams illustrating the melting mechanisms beneath ocean ridges. At any one pressure, the mantle melts over a temperature range of several hundred degrees. The boundary between melt absent and melt present is called the mantle solidus. As mantle ascends beneath the ocean ridge, it begins melting as the solidus is crossed, and melts progressively during further ascent. Thus, the mantle melts by pressure decrease rather than by temperature increase. Hot mantle crosses the solidus at greater depths, leading to a larger melting regime, greater extents of melting, and thicker crust than that produced by cold mantle. The numbers on the bottom diagrams correspond to the pressures where melting stops for the numbered flow lines on the upper diagrams. 


\section{A FIRST-ORDER MODEL FOR OCEAN-RIDGE MELTING}

The deep mantle is solid, but not brittle. At the high temperatures and pressures characteristic of Earth's interior, the mantle beneath the plates flows like a very viscous liquid at rates of up to several tens of centimeters per year. As the rigid plates separate at mid-ocean ridges, the deeper mantle rises to fill the "gap" created by spreading. The ascending mantle crosses its melting point and begins to melt. The mantle-melting region beneath the ridge, the "melting regime," is roughly triangular in shape (see Figure 1). The total amount of melt that can be produced by any particular part of the mantle within the melting regime is proportional to how far this mantle rises after crossing the solidus. The melting regime ranges in extent of melting, therefore, from zero at the bottom where the mantle begins to melt, to a maximum at the shallowest point of melting. The remarkable fact is that as the mantle melts more and more, it is at lower and lower temperatures, so it actually melts while cooling down rather than while heating up.

Because the melts produced in the melting regime are buoyant and fluid, they separate from the solid and rise to the surface to form the oceanic crust. If the mantle is hotter, it starts to melt deeper, and therefore can melt over a

CHARLES H. LANGMUIR (langmuir@ eps.harvard.edu) is Professor, Department of Earth and Planetary Sciences, Harvard University, Cambridge, MA, USA. DONALD W. FORSYTH is Professor, Department of Geological Sciences, Brown University, Providence, RI, USA. larger range of pressures, leading to greater extents of melting. Here, then, the common-sense intuition holds true: hot mantle melts more than cold mantle. The greater quantity of melt from hot mantle thus produces thicker oceanic crust than is produced from colder mantle (see Figure 1). All of this can be understood as a consequence of how the pressure-temperature diagram relates to the melting regime created by mantle flow driven by plate separation.

The actual extent of mantle melting can be estimated from the chemical compositions of the basalts that rise to the surface and are sampled at ocean ridges. Elements that are preferentially concentrated into the liquid (that is to say, elements that are incompatible with the crystals remaining in the solid mantle, called "magmaphile" elements) have concentrations that are inversely proportional to the extent of melting. The most abundant element with this behavior is sodium. High extents of melting lead to liquids with low sodium concentrations, and low extents of melting to high concentrations, because most of the "incompatible" sodium is partitioned into the first small melt fraction. Further melting then dilutes the sodium concentration.

A physical measure of the extent of melting is the amount of crust produced per increment of spreading, which is the crustal thickness. Crustal-thickness measurements are difficult and expensive because they require seismic experiments using instruments deployed on the seafloor. A useful proxy for crustal thickness comes from Archimedes's buoyancy principle: A thick piece of wood sticks up higher out of the water than a thin piece, and also extends deeper below the water. The same principle applies on Earth to crust "floating" on the denser mantle. Oceanic crust is denser and thinner than continental crust, and for this reason the ocean floor is generally at a lower elevation than continents. Variations in the thickness of the oceanic crust along ocean ridges lead to variations in the elevation of the ocean floor, with thick crust, in areas such as Iceland, actually rising above sea level, and very thin crust lying as much as 5000 meters below sea level.

Putting these considerations together, the first-order prediction is that hotter mantle leads to lower sodium content, thicker crust, and shallow water depths, and colder mantle to higher sodium contents, thinner crust, and greater depths. Observations are in agreement with this prediction, as Figure 2 shows. Quantitative models of this simple picture of mantle melting can to first order successfully account for the composition and thickness of the oceanic crust, and the global variations in depths of the ocean ridges (Klein and Langmuir, 1987; Langmuir et al., 1992). Thus, a simple bathymetric map of the ocean-ridge system could be considered to reflect largely the temperature structure of the underlying mantle.

\section{COMPLEXITIES OF THE MELTING PROCESS}

This first-order understanding is only an initial approach to what we now know is a more diverse and complex set of processes, such as the complexities of mantle flow, mantle composition, and the detailed processes of melt segregation. Let us consider some factors that are not taken into account by the first-order model. 


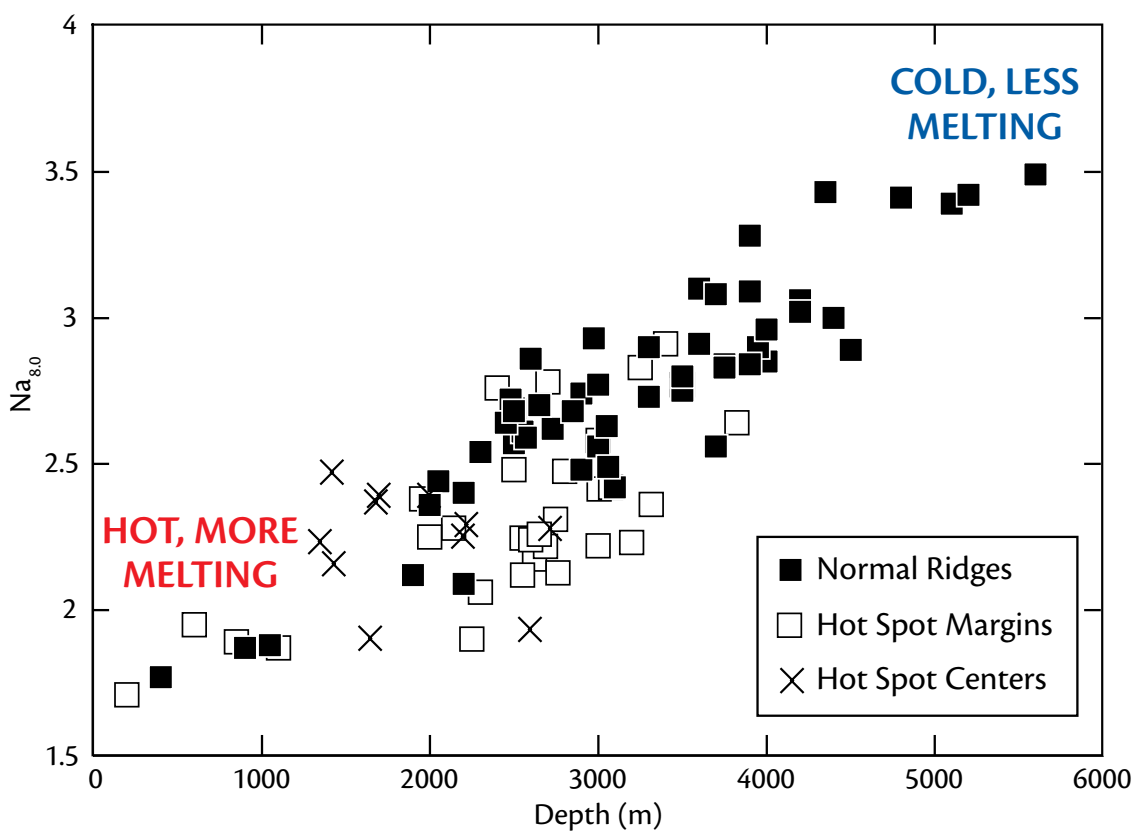

Figure 2. Plots of average compositions of ocean-ridge basalts (each point represents about $100 \mathrm{~km}$ of ridge length) vs. the average depth of the ridge. $\mathrm{Na}_{8.0}$ is the composition of basalt normalized to a constant $\mathrm{MgO}$ content of $8 \mathrm{wt} . \%$ to correct for shallowlevel differentiation. High $\mathrm{Na}$ contents reflect small extents of melting, while lower $\mathrm{Na}$ contents reflect higher extents of melting. High extents of melting lead to low Na contents, greater crustal thickness, and shallower depths below sea level, consistent with a model of varying mantle temperature. After Langmuir et al., 1992

\section{Complexities of Melt Segregation}

The model assumes that melt is delivered to the surface without significant interaction with the surrounding mantle and crustal rocks that it traverses. Although this assumption may seem simplistic, it became more conceivable with the discovery that melt can be transported through the mantle in channels of pure olivine (Kelemen et al., 1995), a mineral that has little effect on chemical composition. The potential chemical complexities and ramifications of melt transport are still only beginning to be understood, however, and a full model of mantle melting must ultimately consider both melt generation and melt transport and the chemical consequences of each.

\section{Variations in Mantle Composition}

Sodium contents of erupted magmas are influenced not only by the extent of melting, but also by source composition. Although the mean mantle composition is quite well constrained (McDonough and Sun, 1995), the operation of plate tectonics inevitably leads to variations on a variety of scales, called mantle heterogeneity. Melting beneath an ocean ridge creates some $6 \mathrm{~km}$ of crust enriched in elements such as sodium and titanium, and $60-100 \mathrm{~km}$ of mantle that is depleted in these elements. When this plate is recycled into the mantle at convergent margins, these heterogeneities gradually become mixed, but differences in density and stiffness will preserve variations on some scale (Allegre and Turcotte, 1986). Major chemical heterogeneities can also be caused by other mantle processes such as recycling back into the mantle of the cold lithosphere beneath continents, and within the mantle the movement of melts that do not reach the surface.

Another important aspect of mantle composition that affects how it melts beneath a spreading center is its content of volatiles, principally water and carbon dioxide. Both have very low melting temperatures, and addition of these compounds to the mantle can substantially increase the pressure where melting begins, as we will examine in more detail below.

\section{Variations in Spreading Rate}

Ridges vary in the rate at which they produce new seafloor, from less than $10 \mathrm{~mm} \mathrm{yr}^{-1}$ to nearly $200 \mathrm{~mm} \mathrm{yr}^{-1}$. At spreading rates of $100 \mathrm{~mm} \mathrm{yr}^{-1}$, the upwelling mantle rises from the depth of melting onset to the surface in only about one million years. At $10 \mathrm{~mm} \mathrm{yr}^{-1}$, it takes about ten million years, long enough for the mantle to lose heat by conduction to the surface while it is still rising (Figure 3). At the slowest spreading rates, therefore, the extent of melting decreases, and the average depth of melting increases, compared to fast-spreading rates (Shen and Forsyth, 1995).

\section{Tectonic Complexities}

The Figure 1 cartoon shows a twodimensional slice across a spreading ridge, which is assumed to extend long distances along the ridge axis. The real world is far more interesting. Ridges are offset by transform faults every $100 \mathrm{~km}$ or so, creating a segmented fabric, as 
shown in Figure 4. Upwelling is expected to be slowed in the vicinity of transform faults, and the rising mantle should be cooled by proximity to the colder, older lithosphere across the transform (Fox and Gallo, 1984; Bender et al., 1984). Thus, on a local scale, we would also expect a truncation of the top of the melting regime.

Ridges are also punctuated periodi- cally by "hotspots," such as those found near Iceland, the Galápagos, and the Azores islands (see Dyment et al., this issue). Most scientists consider hotspots to be generated by hot plumes rising from the deep mantle in "active" mantle flow, rather than the passive mantle flow at ridges that we considered in the first-order model. Active flow generates a different pattern of mantle upwelling

beneath the ridge, and a different relationship between extent of melting and crustal thickness. And there is evidence from trace elements and radiogenic isotopes that the mantle at hotspots may have a composition different from that found under normal ridges, creating an additional complexity (e.g., Schilling, 1975; Schilling et al., 1982).

Finally, there are the spreading axes that are closely associated with convergent margins, called back-arc basin spreading centers (see Martinez et al., this issue). Down-going slabs influence the pattern of mantle flow and prevent the kind of simple upwelling seen in Figure 1. Back-arc spreading centers are also influenced by the flux of water and other elements that come from the slab as it subducts (e.g., Gill, 1976; Sinton and Fryer, 1987; Stolper and Newman, 1994; Taylor and Martinez, 2003). Simple consideration of the geometry also indicates that there may not be enough room in the mantle wedge above the slab to accommodate a melting regime such as is observed at open-ocean ridges (Kelley et al., 2006; Langmuir et al., 2006b).

\section{TESTING MULTI-}

\section{DIMENSIONAL CONTROLS ON MANTLE MELTING}

This overview of the diverse oceanridge environments shows that there are many "forcing functions" that influence the ridge. Understanding the diverse influences of all these forcing functions continues to be a focus of ocean-ridge research.

The classic approach to such ques-

Figure 3. Map of the Arctic Ocean's Gakkel Ridge, which is the slowest major spreading ridge on Earth. Spreading rate decreases progressively towards Siberia, as evident from the narrowing of the basin created by the spreading (delimited by the red lines). As spreading rate declines, slower upwelling prevents melting all the way to the surface, and the melting regime becomes progressively truncated, leading to a melting trapezoid rather than a melting triangle such as seen in Figure 1.

tions in many other areas of scientific research is to carry out experiments in the laboratory where the boundary 
conditions can be controlled, and the experiment completed in weeks to years. Much research in earth science cannot be addressed in this way because the relevant scales of time and space are millions of years and hundreds of kilometers. It is not possible to go to a ridge and turn up the spreading rate or turn down the mantle temperature to see what happens or to build a functioning ridge in the lab. Instead, earth scientists have to make use of "natural experiments" provided by the earth. The following are examples of such experiments and a brief discussion of what they reveal about the diverse influences on mantle melting and crust formation. Many other examples from other portions of the ocean-ridge system can be found in the literature.

\section{Transects Across the Azores and Galápagos Platforms}

The first project of the InterRidge program was a targeted series of investigations across the Azores platform in the Atlantic Ocean to see how a near-ridge hotspot influenced the ridge (Detrick et al., 1995; Langmuir et al., 1997; Asimow et al., 2004). More recently, a similar investigation of the Galápagos Rise took place, traversing the platform created by the Galápagos hotspot in the equatorial Pacific (Cushman et al., 2004).

Around the Azores and Galápagos, the ridge varies in depth from greater than $3000 \mathrm{~m}$ some thousand kilometers from the hotspot to less than $1500 \mathrm{~m}$ where the ridge most closely approaches the hotspot. In earlier studies of these regions, Schilling et al. $(1980,1982)$ showed that the contents of volatiles, such as water in the spreading-axis magmas, increased toward the hotspots' centers as ridge depth shallowed, and that "hotspots" were also "wet spots." Bonatti (1990)

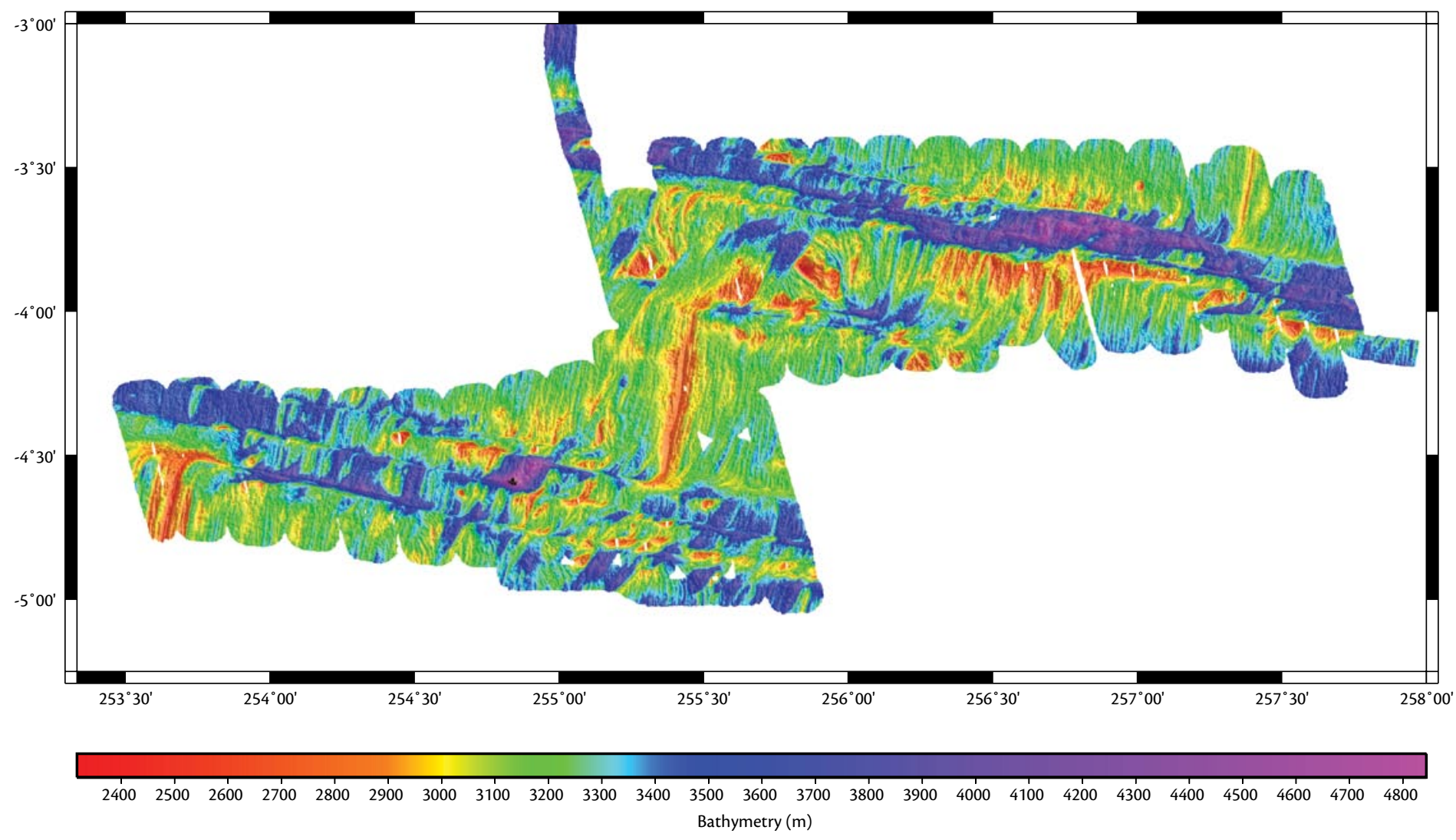

Figure 4. Map of the East Pacific Rise where there are large transform offsets, illustrating the three-dimensional complexity of the ridge system. Melting regimes cannot be continuous across such long transforms, and the cooling effects of the transforms also truncate the top of the melting regime, leading to melting trapezoids near the transform edges, such as seen in Figure 3. From Forsyth et al. (2006) 
inferred that mantle temperatures

beneath these shallow ridges might even be colder than usual, rather than hotter. Schilling also showed that concentrations of various magmaphile elements also substantially increased, and that the gradient in water depth was associated with a gradient in chemical composition. The natural experiment here, then, was to explore the influence of a hotspot on the spreading center. From the "hot," one would infer higher mantle temperatures, and yet the mantle composition, including the particularly significant volatile abundances, changes towards the hotspot. Both water and temperature augment the extent of mantle melting. Can the relative importance of these variables be separated?
Water is significant to mantle melting because it acts as a melting flux in the mantle and is a "carrier phase" for magmaphilic elements. The melting point of the mantle is substantially lowered by the addition of water, even in small amounts. Each 0.1 percent of water added to the mantle lowers the melting point of the first liquid produced by $150^{\circ} \mathrm{C}-250^{\circ} \mathrm{C}$ (e.g., Gaetani and Grove, 1998; Katz et al., 2003 and references therein). If this effect is added to the melting diagram shown in Figure 1 (Figure 5), it becomes evident that water causes melting to begin at much higher pressures and leads to greater extents of melting at the top of the melting regime (Hirth and Kohlstedt, 1996; Asimow and Langmuir, 2003). Because water, like sodium, is strongly partitioned into the first melts formed, its influence decreases markedly with increasing extent of melting. This leads to very low melt production in the deep part of the melting regime, and a very different distribution of melt with depth. Therefore, water and temperature both lead to increases in total melt production and crustal thickness, and therefore shallower ridge depths, but the effect of water is in the deep, low-degree melts.

Experimental data quantify the effects of water on mantle melting (e.g., Gaetani and Grove, 1998). The challenge is to produce models that yield both the correct crustal thickness and contents of water and other elements in the magmas at the hotspot center. Such models show that the shallow depths and increased
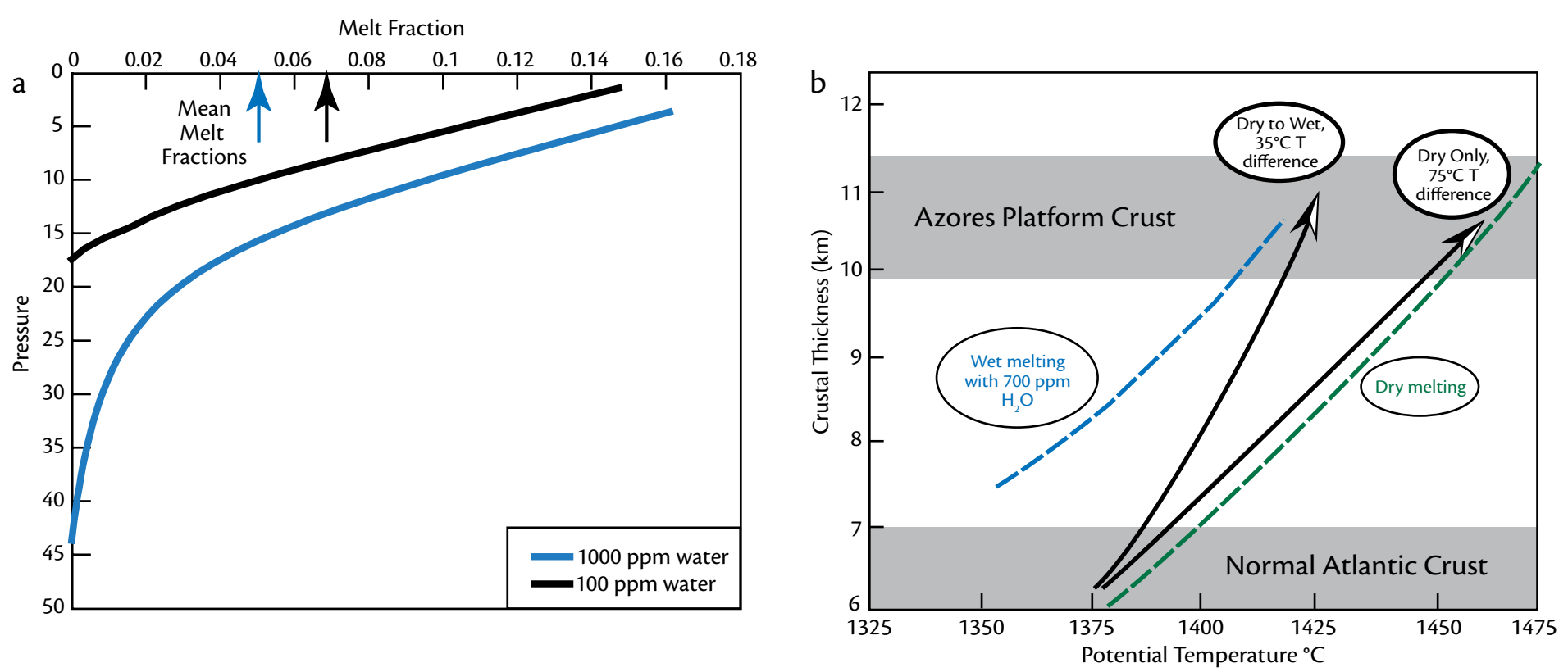

Figure 5. Illustration of the effects of water on melting beneath ridges. The left panel shows that addition of water creates a deep "tail" of low extents of melting, which contributes additional melt and causes greater crustal thickness. Although adding water causes the maximum extent and total amount of melt to increase, the average extent of melting across the whole depth of melting decreases because of the large, deep region of low-degree melts. The right panel shows how this effect can help to explain data from the Azores hotspot. Having a water-rich mantle source reduces the needed temperature excess to explain crustal thickness variations from about $75^{\circ} \mathrm{C}$ to $35^{\circ} \mathrm{C}$. Right-hand panel modified from Asimow et al (2004) 
crustal thickness are the result of both hotspot and wet-spot effects (Asimow et al., 2004). Temperature differences alone would suggest that the ridge near the Azores was some $75^{\circ} \mathrm{C}$ hotter than normal. Inclusion of water shows the addition of some 750 parts per million of water to the mantle leads to the appropriate chemical compositions and crustal thickness, and this reduces the temperature differences required to some $35^{\circ} \mathrm{C}$ (Asimow et al., 2004).

\section{The MELT Seismic Experiment on the Southern East Pacific Rise}

The various models of mantle melting outlined above are based on information derived from experiments on peridotite melting and calculations of mantle tem- perature structure. Direct ground-truth tests of how the mantle actually melts require imaging the melting regime beneath the ridge axis. The Mantle Electromagnetic and Tomography (MELT) seismic experiment was designed to image the mantle beneath a spreading axis using seismic and electromagnetic methods (MELT Seismic Team, 1998). The ideal location for this investigation was the equatorial East Pacific Rise, which is characterized by a long ridge with few transform offsets, a high spreading rate and therefore maximum rate of melt production, and good weather.

The experiment showed that, unlike beneath hotspot islands, there was no deep "root" of anomalously hot mantle extending hundreds of kilometers below the surface (Figure 6). This lack of a deep root confirms that upwelling at this spreading center is passively driven by plate separation rather than by active convective upwelling. Seismic shearwave velocities dropped dramatically at depths above $100-150 \mathrm{~km}$, indicating the onset of melting (shear or " $\mathrm{s}$ " waves cannot propagate through liquid). Because experiments on peridotite melting show that volatile-free mantle should begin to melt only at $60-80 \mathrm{~km}$, the presence of melt at greater depths inferred from the MELT results indicate that, even in the absence of a hotspot or wet-spot influence, the effects of water on melting regime are important.

Some theoretical models had suggested that once melting began, mantle

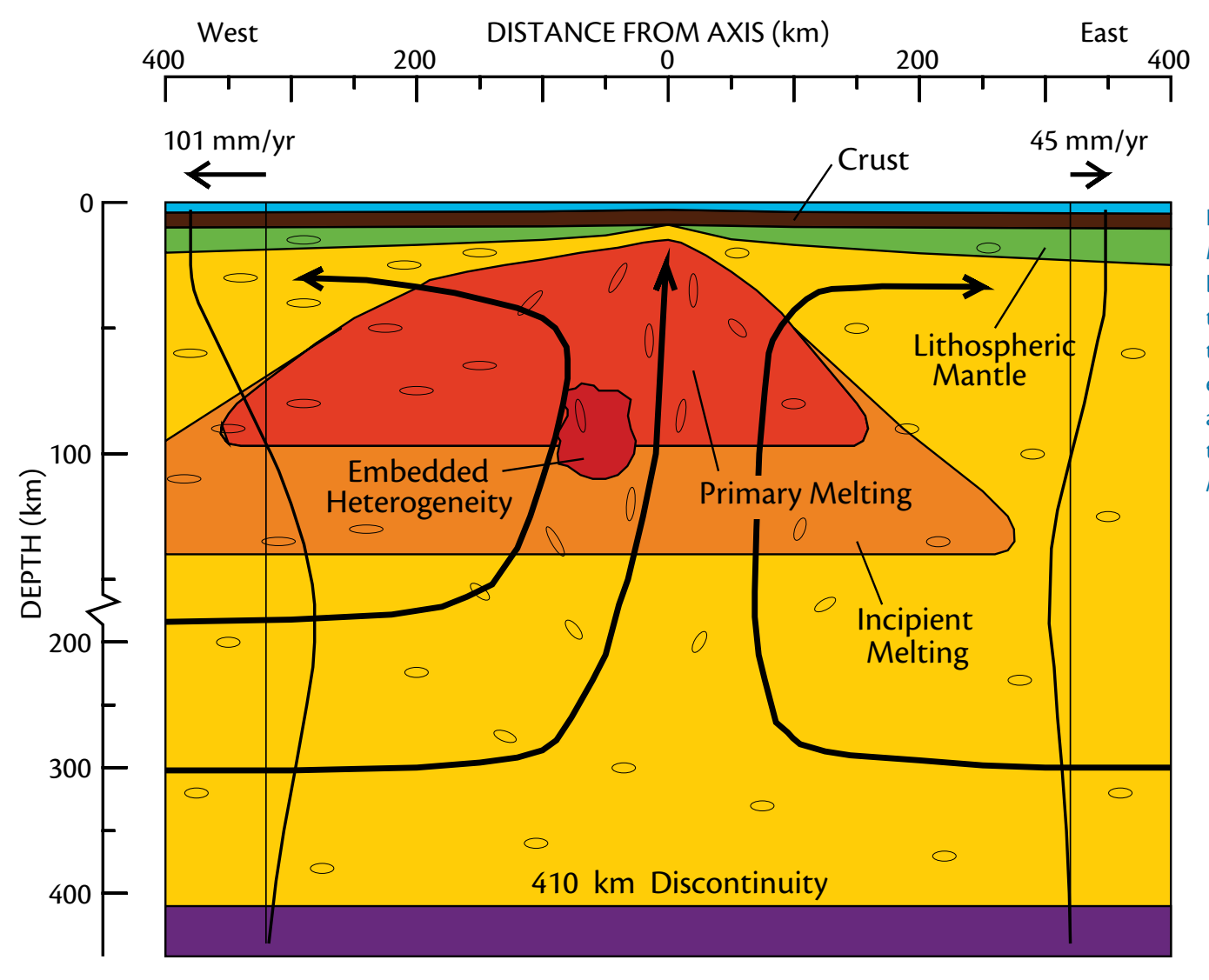

Figure 6. Schematic of results from the MELT experiment, showing that melting begins at about $150-\mathrm{km}$ depth and that the melting regime extends preferentially to the west of the East Pacific Rise. This experiment was the first attempt to image an ocean-ridge melting regime, testing the conceptual cartoons seen in Figure 1. Modified from the MELT Seismic Team, 1998 
upwelling might concentrate into a very narrow zone directly beneath the spreading axis. Instead, the low-velocity zone was more than $100 \mathrm{~km}$ across, consistent with the roughly triangularly shaped region of melting shown in Figure 1. The electromagnetic experiment showed that the upper 60 to $70 \mathrm{~km}$ of the mantle away from the spreading center itself is highly resistive, indicating that the mantle above this depth has been depleted of water by the removal of melt (Evans et al., 2005). Perhaps the most surprising result was the degree of asymmetry of structure beneath the East Pacific Rise, with lower seismic velocities, shallower seafloor, and more pronounced seismic anisotropy associated with alignment of olivine crystals. This result suggested that deeper flow in the mantle (to supply the material flowing in to fill the gap left by the separating plates) comes primarily from the west, perhaps supplied by hotspots beneath Tahiti and other islands far from the spreading center (Mahoney et al., 1994; Phipps Morgan et al., 1995; Toomey et al., 2002; Conder et al., 2002).

Investigation of the Gakkel Ridge, Arctic Ocean

One of the most interesting spreading centers on Earth, the Gakkel Ridge, lies beneath the ice of the Arctic Ocean and extends from Greenland to Siberia (see Figure 3). Studying this ridge is fraught with operational difficulties. InterRidge scientists invested considerable time and effort in devising a plan to begin studying this ridge, a plan that came to fruition in 2001 with the two-ship AMORE expedition involving the new US icebreaker, the Coast Guard cutter Healy, and the German icebreaker Polarstern (see Snow and Edmonds, this issue). The Gakkel is the slowest-spreading ridge in the world, with spreading rates from 6-15 $\mathrm{mm} \mathrm{yr}^{-1}$. It has no transform offsets or hotspots that would lead to perturbations in mantle temperature. This simple geometry is ideal for an investigation of the role of spreading rate on mantle melting (Michael et al., 2003). Simple thermal models suggest that at these low spreading rates there would be a substantially increased lid of cold lithosphere and lower extents of melting. If variations in lithospheric thickness rather than mantle temperature cause the variations in crustal thickness and magma chemistry observed along ridges, then variations along the Gakkel Ridge should mirror global trends. Or, can the important variables of spreading rate and mantle temperature be separated? Analyses of the wealth of data from this expedition are well underway. The critical chemical parameters turned out to be the basalts' iron and silica concentrations, and the distribution of the rare earth elements, whose pattern of distribution is sensitive to melting pressure. The results clearly show the effects of increased lithospheric thickness on the melting regime, as distinct from those caused by mantle temperature differences (Langmuir et al., 2006b).

\section{The Quebrada-Discovery-Gofar Fracture Zone System}

The Quebrada, Discovery, and Gofar fracture zones are a set of transform faults on the fast-spreading East Pacific Rise. Within each transform, there are short, intra-transform spreading centers from $5-15 \mathrm{~km}$ in length, which are offset by different distances from the primary spreading centers (Figure 4). This area provides a natural laboratory to test models of the three-dimensional pattern of mantle flow and melt migration. If melting occurs in broad, triangular zones beneath the ridges as shown in Figure 1, how does the melt from the distal portions of the melting regime migrate laterally back to the ridge axis? Several ideas have been suggested, such as melt migrating vertically to the top of the melting region, then flowing up along the base of the sloping lithosphere back to the spreading center (Magde and Sparks, 1997). Another suggestion is that the melts are driven by pressure gradients within the deforming solid mantle (Phipps Morgan, 1987; Spiegelman and McKenzie, 1987). These models make different predictions for the composition and volume of melt that would be delivered to each intra-transform spreading center.

A research cruise in April 2006 (Forsyth et al., 2006) mapped the bathymetry in detail, made gravity measurements to estimate differences in crustal thickness, and sampled basalts. The composition of the basalts will reveal the relative contributions of deep and shallow melting to the crust that is formed at each intra-transform center, thus helping to decipher the plumbing system that pipes magma out of the mantle and the effect of transform offsets on melt production.

The Lau Basin Back-Arc Spreading Center

Back-arc basins provide another natural experiment for ocean-ridge processes because of their unique thermal and tectonic environments. The Lau backarc basin formed behind the northeast- 
southwest trending Tonga volcanic arc, which itself was formed by subduction of the Pacific Plate at the Tonga trench (Figure 7). Situated west of the arc, the southern Lau Basin is relatively young ( $<5.5$ million years old) oceanic crust created by two main rifts, the Central Lau Spreading Center and the Eastern Lau Spreading Center. From south to north, the spreading rate increases from $65 \mathrm{~mm} \mathrm{yr}^{-1}$ at $21^{\circ} \mathrm{S}$ to $90 \mathrm{~mm} \mathrm{yr}^{-1}$ at $18^{\circ} \mathrm{S}$ (Taylor et al., 1996; Martinez et al., 2006), as distance between the ridge and the arc front also increases. These conditions make the Lau Basin an ideal backarc environment for addressing issues such as transport of fluid components from slab to mantle wedge, the timing of these transport processes, and the influence of slab fluids on mantle melting. To take advantage of this unique tectonic setting, the US Ridge 2000 program designated the Lau Basin an "integrated study site." Japanese, British, German, and Australian investigators have also made substantial contributions to the understanding of this region.

Back-arc basins are important from the mantle melting perspective because water is added from dehydration of the subducting slab, and the influence of water contrasts markedly with its influence at open-ocean ridges. Plotting an index of the extent of melting (such as the $\mathrm{TiO}_{2}$ or $\mathrm{Na}_{2} \mathrm{O}$ contents) vs. $\mathrm{H}_{2} \mathrm{O}$ contents, indicates opposite trends in the back-arc and open ocean. This result can be understood visually by placing the melting regime seen in Figure 1 within

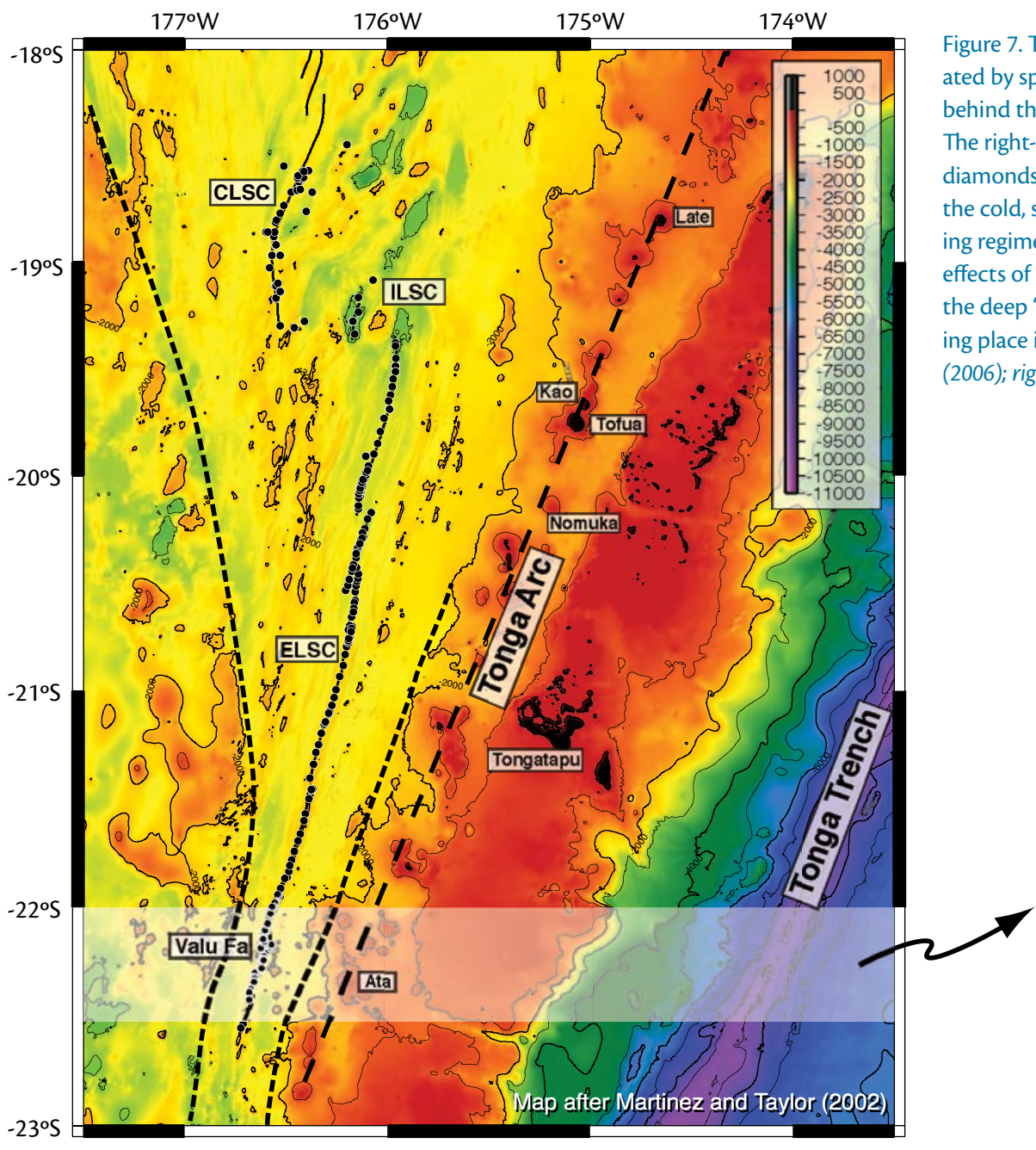

Figure 7. The left-hand panel shows the Lau Back-Arc Basin created by spreading along the Eastern Lau Spreading Center (ELSC) behind the Tonga arc, where the Pacific Plate is being subducted. The right-hand panel shows a cross section at about $22^{\circ} \mathrm{S}$. The grey diamonds are earthquake locations that indicate the position of the cold, subducting plate. There is no room for a triangular melting regime in this environment-the slab truncates it. Thus, the effects of hydrous melting seen in Figure 5, which are the result of the deep "wings" of the melting regime, are prevented from taking place in the back-arc environment. Map from Martinez et al. (206); right-hand panel modified from Langmuir et al. (2006a)

Distance from the Tonga trench $(\mathrm{km})$

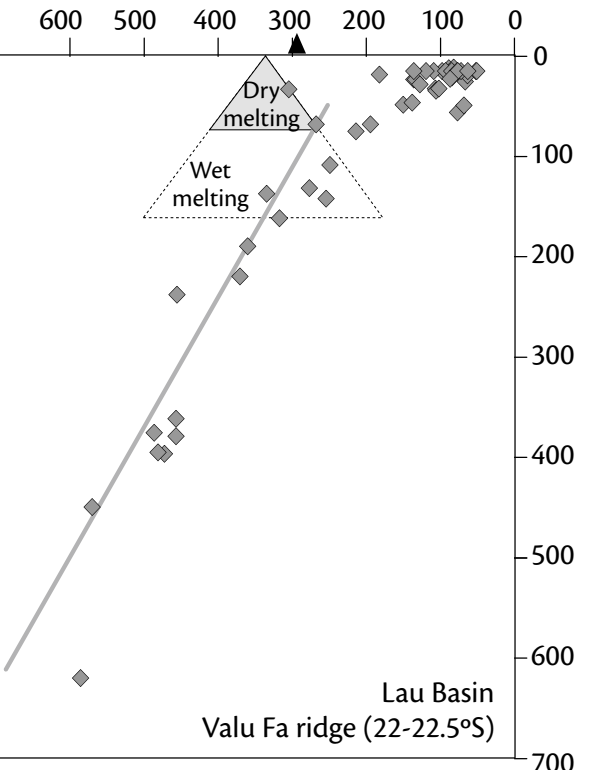


the context of a back-arc such as the southern Lau Basin (Figure 7b). There is no room for it! In the open ocean, the effects of water lowering the mean extent of melting come from the "wings," or distal edges, of the melting regime.

And in the back-arc, there is no room for the extremities of the melting regime on the arc side of the system, exactly where the subducting plate might be introducing water into the mantle. Therefore, in the back-arc it seems likely that melts from the two halves of the melting regime have very different characteristics. On the back-arc, or dry side, melting is similar to open-ocean ridges. On the arc side, or wet side, the flux of water occurs at shallow pressures, leading to substantially increased melting. Mixing of melts from these two diverse environments may create the distinctive backarc data arrays.

\section{FUTURE PERSPECTIVES}

Ocean ridges are the largest tectonic landforms on earth. They are remarkably inaccessible because they are far from land, hidden beneath thousands of meters of water, and often lie in the most remote portions of the globe where weather conditions are some of the most difficult. While studies over the last three decades have led to substantial progress, we are still at a very early stage of understanding. No ocean-ridge volcano has anywhere near the monitoring and historical record that are common on land. For example, the Smithsonian Catalogue of Volcanoes of the World (Simkin and Siebert, 1994) reports thousands of eruptions from subaerial volcanoes. In contrast, only a handful of undersea eruptions are known. Ocean-ridge science remains a frontier.

With sustained funding, it seems likely that over the next 10-15 years, better constraints from all parts of the system will lead to an integrated understanding of mantle melting beneath ridges. These constraints will likely arise from the following complement of directions:

1. Although there are many samples from ocean ridges, few of them have relatively complete geochemical analyses, which are crucial to test models of melting and mantle heterogeneity. Comprehensive data sets are likely to provide much clearer constraints.

2. Over the next 10-15 years, the ridges may become completely sampled on a global scale. Several "natural experiments" remain in logistically remote regions that will provide a broader range of "forcing functions" with which to constrain melting models.

3. Imaging of the ridge on global and local scales will be improved by steady progress in seismology. Global seismic arrays will lead to much better constraints on temperature, melt production, and mantle flow. Local seismic experiments focused on different ridges with the full range of spreading characteristics will enable imaging of the melting regime and how it varies.

4. More experimental data, particularly on the influence of volatiles on melt compositions and the consequences of melting of a lithologically heterogeneous mantle, will provide constraints on how melt composition varies with the composition and lithology of the mantle source.

5. All of these data can be best assimilated and new hypotheses generated by integrated models of mantle melt- ing that incorporate mantle flow, melt migration, and crystallization in the context of three-dimensional mantle flow and tectonic environments that reflect the fascinating complexities of the real earth.

\section{ACKNOWLEDGEMENTS}

This manuscript benefited from reviews by Colin Devey and John Sinton, and the careful editing of Kristen Kusek, whose efforts are much appreciated. Research was supported by the National Science Foundation. 包

\section{REFERENCES}

Allegre, C., and D.L. Turcotte. 1986. Implications of a two component marble cake mantle. Nature 323:123-127.

Asimow, P.D., and C.H. Langmuir. 2003. The importance of water to oceanic mantle melting regimes. Nature 421:815-820.

Asimow, P.D., J.E. Dixon, and C.H. Langmuir. 2004 A hydrous melting and fractionation model for mid-ocean ridge basalts: Application to the Mid-Atlantic ridge near the Azores. Geochemistry, Geophysics and Geosystems 5:Q01E16, doi:10.1029/2003GC000568.

Baker, M.B., and E.M. Stolper. 1994. Determining the composition of high-pressure mantle melts using diamond aggregates. Geochimica Cosmochimica Acta 58:2,811-2,827.

Bender, J.F., C.H. Langmuir, and G.N. Hanson. 1984. Petrogenesis of basalt glasses from the Tamayo region, East Pacific Rise. Journal of Petrology 25:213-254.

Bonatti, E. 1990. Not so hot "hot spots" in the oceanic mantle. Science 250:107-111.

Conder J.A., D.W. Forsyth, and E.M. Parmentier. 2002. Asthenospheric flow and asymmetry of the East Pacific Rise, MELT area. Journal of Geophysical Research 107(B12):2344, doi:10.1029/ 2001JB000807.

Cushman, B., J. Sinton, G. Ito, and J.E. Dixon. 2004. Glass compositions, plume-ridge interaction, and hydrous melting along the Galápagos Spreading Center, $90.5^{\circ} \mathrm{W}$ to $98^{\circ} \mathrm{W}$. Geochemistry, Geophysics and Geosystems 5:Q08E17, doi:10.1029/2004GC000709.

Detrick, R.S., H.D. Needham, and V. Renard. 1995. Gravity anomalies and crustal thickness variations along the Mid-Atlantic Ridge between 
$33^{\circ} \mathrm{N}$ and $40^{\circ} \mathrm{N}$. Journal of Geophysical Research 100:3,767-3,788.

Evans, R.L., G. Hirth, K. Baba, D. Forsyth, A. Chave, and R. Mackie. 2005. Geophysical evidence from the MELT area for compositional controls on oceanic plates. Nature 437:249-252.

Forsyth, D.W., N. Harmon, R.C. Pickle, and A. Saal. 2006. Stability and instability in an evolving oceanic transform fault system. Eos, Transactions, American Geophysical Union 87(52), Fall Meeting Supplement, Abstract T42C-01.

Fox, P.J., and D.G. Gallo. 1984. A tectonic model for ridge-transform-ridge plate boundaries: Implications for the structure of oceanic lithosphere. Tectonophysics 104(3-4): 205-242.

Gaetani, G.A., and T.L. Grove. 1998. The influence of water on melting of mantle peridotite. Contributions to Mineralogical Petrology 131:323-346.

Gill, J.B. 1976. Composition and age of Lau Basin and ridge volcanic rocks: Implications for evolution of an interarc basin and remnant arc. Geological Society of America Bulletin 87:1,3841,395 .

Hirth, G., and D.L. Kohlstedt. 1996. Water in the oceanic upper mantle: Implications for rheology, melt extraction and the evolution of the lithosphere. Earth and Planetary Science Letters 144:93-108.

Jaques, A.L., and D.H. Green. 1980. Anhydrous melting of peridotite at $0-15 \mathrm{~kb}$ pressure and genesis of tholeiitic basalts. Contributions to Mineralogical Petrology 73:287-310.

Katz, R.F., M. Spiegelman, and C.H. Langmuir. 2003. A new parameterization of hydrous mantle melting. Geochemistry, Geophysics, Geosystems 4:9, doi:10.1029/2002GC000433.

Kelemen, P.B., N. Shimizu, and V.J.M. Salters. 1995. Extraction of MORB from the mantle by focused flow of melt in dunite channels. Nature 375:747-753.

Kelley, K.A, T. Plank, T.L. Grove, E.M. Stolper, S. Newman, and E. Hauri. 2006. Mantle melting as a function of water content beneath backarc basins. Journal of Geophysical Research 111: B09208, doi:10.1029/2005JB003732.

Kinzler, R.J., and Grove, T.L. 1992. Primary magmas of mid-ocean ridge basalts. 1. Experiments and methods. Journal of Geophysical Research 9: 6885-6906.

Klein, E.M., and C.H. Langmuir. 1987. Global correlations of ocean ridge basalt chemistry with axial depth and crustal thickness. Journal of Geophysical Research 92:8,089-8,115.

Langmuir, C.H., E.M. Klein, and T. Plank. 1992. Petrological systematics of mid-ocean ridge basalts: Constraints on melt generation beneath ocean ridges. Pp. 183-280 in Mantle Flow and Melt Generation at Mid-Ocean Ridges. J. Phipps
Morgan, D.K. Blackman, and J.M. Sinton, eds, American Geophysical Union, Washington, DC.

Langmuir, C.H., A. Bézos, S. Escrig, and S.W. Parman. 2006a. Chemical systematics and hydrous melting of the mantle in back-arc basins, Pp. 87-146 in Back-Arc Spreading Systems: Geological, Biological, Chemical, and Physical Interactions. D.M. Christie, C.R. Fisher, S.-M. Lee, and S. Givens, eds, Geophysical Monograph Series, Volume 166, American Geophysical Union, Washington, DC.

Langmuir, C.H., J. Standish, P. Michael, and S. Goldstein. 2006b. Constraints on ocean ridge basalt generation from Gakkel Ridge basalts. Eos, Transactions, American Geophysical Union 87(52), Fall Meeting Supplement, Abstract V12c-01.

Magde, L.S., and D.W. Sparks. 1997. Three-dimensional mantle upwelling, melt generation and melt migration beneath segmented slowspreading ridges. Journal of Geophysical Research 102(B9):20,571-20,585.

Mahoney, J.J., J.M. Sinton, M. Kurz, J.D. Macdougall, K.J. Spencer, and G.W. Lugmair. 1994. Isotopic and trace element characteristics of a super-fast spreading ridge: East Pacific Rise, $13-23^{\circ}$ S, Earth and Planetary Science Letters 121: 173-193.

Martinez, F., B. Taylor, E.T. Baker, J.A. Resing, and S.L. Walker. 2006. Opposing trends in crustal thickness and spreading rate along the back-arc Eastern Lau Spreading Center: Implications for controls on ridge morphology, faulting, and hydrothermal activity. Earth and Planetary Science Letters 245:665-672.

McDonough, W.F., and S.-S. Sun. 1995. Composition of the Earth. Chemical Geology 120:223-253.

MELT Seismic Team. 1998. Overview of the seismological component of the MELT Experiment. Science 280:1,215-1,218.

Michael, P.J., C.H. Langmuir, H.J.B. Dick, J.E. Snow, S.L. Goldstein, D.W. Graham, K. Lehnert, G. Kurras, W. Jokat, R. Mühe, and H.N. Edmonds. 2003. Magmatic and amagmatic seafloor generation at the ultraslow-spreading Gakkel Ridge, Arctic Ocean. Nature 423:956.

Phipps Morgan, J. 1987. Melt migration beneath mid-ocean spreading centers. Geophysical Research Letters 14:1238-1241.

Phipps Morgan, J., W.J. Morgan, Y.-S. Zhang, and W.H.F. Smith. 1995. Observational hints for a plume-fed, sub-oceanic asthenosphere and its role in mantle convection. Journal of Geophysical Research 100:12,753-12,767.

Pickering-Witter, J., and A.D. Johnston. 2000. The effect of variable composition on the melting systematics of fertile peridotitic assemblages. Contributions to Mineralogical Petrology
140:190-211.

Schilling, J.G. 1975. Azores mantle blob: Rare-earth evidence. Earth and Planetary Science Letters 25:103-115.

Schilling, J.G., M.B. Bergeron, and R. Evans. 1980. Halogens in the mantle beneath the North-Atlantic. Philosophical Transactions of the Royal Society, Series A: Mathematical, Physical, and Engineering Sciences 297:147-178.

Schilling, J.G., H. Kingsley, and J.D. Devine. 1982. Galapagos hot spot - spreading center system. 1. Spatial petrological and geochemical variations $\left(83^{\circ} \mathrm{W}-101^{\circ} \mathrm{W}\right)$. Journal of Geophysical Research 87:5,593-5,610.

Shen, Y., and D.W. Forsyth. 1995. Geochemical constraints on initial and final depths of melting beneath ocean ridges. Journal of Geophysical Research 100 (B2):2,211-2,237.

Simkin, T., and L. Siebert. 1994. Volcanoes of the World, second edition. Geoscience Press, Inc., Tucson, Arizona, 349 pp.

Sinton, J.M., and P. Fryer. 1987. Mariana Trough lavas from $18^{\circ} \mathrm{N}$ : Implications for the origin of back-arc basin basalts. Journal of Geophysical Research 92:12,782-12,802.

Spiegelman, M., and D. McKenzie. 1987. Simple 2-D models for melt extraction at mid-ocean ridges and island arcs. Earth and Planetary Science Letters 83:137-152.

Stolper, E., and S. Newman 1994. The role of water in the petrogenesis of Mariana Trough magmas. Earth and Planetary Science Letters 121:293-325.

Taylor, B., and F. Martinez. 2003. Back-arc basin basalt systematics. Earth and Planetary Science Letters 210:481-497.

Taylor, B., K. Zellmer, F. Martinez, and A. Goodliff. 1996. Sea-floor spreading in the Lau backarc basin. Earth and Planetary Science Letters 144:1, 35-40.

Toomey, D.R., W.S.D. Wilcock, J.A. Conder, D.W. Forsyth, J. Blundy, E.M. Parmentier, and W.C. Hammond. 2002. Asymmetric mantle dynamics in the MELT region of the East Pacific Rise. Earth and Planetary Science Letters 200:287-295. 